\title{
El derecho del rey a hacer la guerra en el Antiguo Testamento
}

Javier Quezada del Río

Para citar este artículo: Quezada del Río, Javier. "El derecho del rey a hacer la guerra en el Antiguo Testamento". Franciscanum 161, Vol. LVI (2014): 153-173.

\section{Resumen}

El autor analiza tres estadios del derecho del rey a hacer la guerra en el Antiguo Testamento: durante la conquista, a través del estudio semántico de la palabra jerem; durante el inicio de la monarquía, comparando las tradiciones monárquica y antimonárquica del primer libro de Samuel; y en los salmos mesiánicos o reales. Llega a la conclusión de que en todos los estadios el rey hacía la guerra de la mano de Dios, no solo contra los enemigos que atacaban a Israel, sino también para sojuzgar a las naciones, pues dominarlas era el destino del pueblo elegido.

\section{Palabras clave}

Rey, jerem, guerra, anatema, David.

Licenciado y maestro en teología. Doctor en filosofía. Profesor investigador el Departamento de Ciencias Religiosas en la Universidad Iberoamericana, Ciudad de México, desde el año 2000. Fue presidente de la Asociación de Biblistas de México del 2010 al 2012. Contacto: javier.quezada@uia.mx. 


\title{
The king's right to make war in the Old Testament
}

\begin{abstract}
The author analyses three moments of the king's right to make war in the Old Testament: during de conquest, through the semantic study of the word herem; at he beginning of the monarchy, comparing the monarchic tradition and the antimonarchic one in the first book of Samuel; and in the messianic psalms. He concludes that in the three moments, the king made war on the hand of God, not only against the enemies attacking Israel, but also to conquest the nations, because dominate them was the destiny of the elected people.
\end{abstract}

\section{Keywords}

King, herem, war, anathema, David.

\section{Introducción}

Muchas de las guerras del pasado se justificaron en textos o en la fe bíblica. Dicha justificación se hizo a partir de los métodos de interpretación de la Biblia, corrientes en su época. Esto es cierto tanto para el judaísmo como para el cristianismo. Así como fray Bartolomé de las Casas y Alonso de la Veracruz fundamentaron en su manera de entender la Biblia, su crítica a la guerra de conquista, en la literatura judía se ha dedicado cada vez más espacio a discutir cuáles son los fundamentos bíblicos y halákhicos que pueden justificar una guerra por parte del Estado de Israel ${ }^{1}$.

1 Cf. Stuart Cohen, «Unlicensed War in Jewish Tradition: Sources, Consequences and Implications», Journal for Military Ethics 3, Vol. 4 (2005): 198-213. 
Cada vez es más claro que los textos bíblicos no pueden aislarse de su contexto y esgrimirse como normas válidas en todo tiempo y lugar. Por ello, han venido tomando importancia los análisis monográficos sobre diferentes temas (teología bíblica). El estudio sistemático de la guerra, especialmente en el Antiguo Testamento es muy pobre ${ }^{2}$, a pesar de que es ubicua. Lo que la Biblia dice en general sobre la guerra es muy contrastante con lo que actualmente se piensa de ella. Cualquier lector de la Biblia se ha encontrado con pasajes absolutamente indigestos en los que Dios mismo es un guerrero al frente de su ejército y aniquila armadas, pueblos y naciones enteras. Esto plantea otro problema, si no es válida una exegesis que pretenda erigir una frase o un texto como la palabra definitiva de la Biblia, ies obligada la obediencia a lo que la Biblia dice en general? Las respuestas son muy diferentes y este no es el espacio para discutirlas. Nos centraremos exclusivamente en qué dice El Antiguo Testamento sobre el derecho del rey a hacer la guerra, paso previo a cualquier teología de la guerra.

Tal vez el libro que más retórica sobre la guerra tiene sea el de Josué. En él, Dios mismo impulsa a los israelitas a tomar la tierra de Canaán y aniquilar a los pueblos conquistados. Y todo eso en una íntima alegría y serenidad de que Yahveh cumple sus promesas. Josué no era el rey de Israel, por eso el derecho de guerra lo poseía Dios mismo, aunque lo realizaba por medio de su elegido para dirigir al pueblo en sustitución de Moisés. En la primera parte de este artículo analizamos brevemente la palabra jerem (destrucción total del pueblo conquistado, aniquilamiento de lo que represente un peligro para la fe $)^{3}$, ya que en este libro se usa con frecuencia. La expresión más autorizada y formal de la guerra llamada santa -término que no se

2 Hizo esta constatación Kuan Jeffey Kan-Jin, «Biblical Interpretation and the Rhetoric of Violence and War», Asia Journal of Theology 23 (2009): 189-203.

3 Para la definición del sentido de jerem: J. P. U. Lilley, «Understanding the Herem», Tyndale Bulletin 1, Vol. 44 (1993): 171. He aquí la definición de Mayes que Lilley reporta: «es el exterminio del enemigo en la guerra santa y la reserva de algunas cosas que se hace para Yahweh. El factor común es que las cosas así designadas no quedan disponibles para usos comunes». 
usa en la Biblia- está en el Deuteronomio, que recogió y reformuló las tradiciones anteriores ${ }^{4}$.

Al final del período de los jueces, en el inicio de la monarquía, Yahveh, Samuel y el pueblo mismo tenían claro que una de las principales atribuciones del rey era conducir al pueblo a la guerra. En la segunda parte estudio algunos de los textos correspondientes.

El rey por antonomasia en el Antiguo Testamento fue David. De él surgió una ideología real en la que el derecho de guerra es fundamental y está íntimamente unido a la fe en que Dios lucha hombro con hombro las guerras de su pueblo. En la tercera parte veremos qué dicen los salmos mesiánicos sobre el derecho del rey a hacer la guerra.

Ese derecho no se limitó a las etapas premonárquica y monárquica, más bien, la ideología de Yahveh rey guerrero pervivió en el período persa y está presente en los últimos libros del Antiguo Testamento. Aquí no estudio esas épocas por motivos de espacio.

\section{El jerem o anatema}

Sin duda que la costumbre del anatema es chocante con la mentalidad contemporánea y presenta dificultades a todos los que consideran el texto bíblico como inspirado por Dios. El anatema es «un condicionamiento histórico del que no debemos escandalizarnos -dice Sicre-. En la línea propuesta por Stern, Israel (igual que Moab y otros pueblos) veían el jerem como una forma de instaurar el orden en un mundo caótico, en poder de las fuerzas del mal» ${ }^{5}$.

Antes de que hubiera rey en Israel, Dios mismo peleaba a favor de su pueblo. Expresiones como «Dios entregó a (...) en manos de», son muy frecuentes (Dt 3,2.3), aunque se discute si su origen es

\footnotetext{
4 Cf. Reuven Firestone, «Conceptions of Holy War in Biblical and Qur'anic Tradition», Journal of Religious Ethics 24 (1996): 104.

5 José Luis Sicre, Josué (Estella: Verbo Divino, 2002), 60.
} 
premonárquico (Von Rad), proceden de los profetas del norte (Stolz) ${ }^{6}$ o son deuteronomistas. En general, los pueblos del Oriente Medio también consideraban que Dios desempeñaba una parte fundamental en la guerra. Incluso la fraseología de sus textos es muy similar a la de la Biblia.

Israel tenía la costumbre de consagrar al anatema al pueblo conquistado. Dicho anatema consistía en matar a todos los seres vivientes de dicho lugar, una vez derrotado en la batalla. Varios textos muestran que otros pueblos también tenían esa costumbre ${ }^{7}: 2$ R 19,11; Is 37,$11 ; 1 \mathrm{Cr} 4,41 ; 2 \mathrm{Cr} 20,23 ; 32,14$. Hay que notar, sin embargo, que cuando se escriben esos relatos de Reyes, Isaías y Crónicas, ninguno de aquellos pueblos existía, es decir, no se puede achacar a los textos la finalidad de arengar al pueblo en contra de algunos vecinos.

La palabra anatema derivó de destrucción total, a consagración a Yahveh. Hay algunos textos que pueden revelar esta evolución.

Uso de la palabra anatema fuera de la guerra

En el Levítico, la palabra anatema se usó para indicar la parte de un sacrificio que se separaba y que pertenecía a Yahveh (Lv 27,2829). Lo que revela una evolución del concepto debido al rechazo que la idea representaba tardíamente. La expresión también se usó para señalar la condenación a muerte, al menos en el caso de quien sacrificara a otros dioses (Ex 22,19-20). Incluso los israelitas idólatras debían ser entregados al anatema (Dt 13,2-9). En Lv 27,21; Nm 18,14; Ez 44,29 se establece que todo lo que caiga bajo anatema pertenecerá a los descendientes de Aarón. En Dt 7,26 se llama anatema a los ídolos y lo que los recubre, pero es la única ocasión en que los ídolos son llamados jerem; ellos no debían ser consagrados (al anatema), Present Satate of the Question», en Deuterocanonical and Cognate Literature Yearbook (Berlín/New York: Walter de Gruyter GmbH, 2010), 1-34.

7 Por ejemplo Mari (estela de Mesha, rey de Moab, s. viI a.C.): «Lo tomé y lo destruí, 7000 ciudadanos y extranjeros, varones y mujeres, junto con esclavas, pues los había consagrado a Ashtar-Quemosh para su destrucción». Tomado de Frédéric Gangloff, «Joshua 6: Holy War or Extermination by Divine command (Herem)?», Theological Review 1, Vol xxv (2004): 10. 
sino simplemente destruidos ${ }^{8}$. La traducción anatema no es, debido a la variedad de sentidos que la palabra adquiere, completamente adecuada, aunque es una de las traducciones usadas por los LXX (anáthema, excomunión, maldición). Tal vez consagrar al anatema o consagración al anatema sea más justa.

\section{Uso de la palabra anatema en la guerra}

La inmensa mayoría de veces que se habla del anatema, se trata de que todo ser viviente de una ciudad conquistada debe ser aniquilado, aunque con frecuencia el jerem no se aplicó tan radicalmente. En Nm 21,1-3, se habla de la entrega de Jormá al anatema. Esa entrega dio el nombre a la ciudad (Jormá procede del hebreo jerem, anatema, y del verbo jaram, entregar al anatema). La misma explicación, pero en época diferente se da en Jc 1,17.

Yahveh mismo mandó consagrar al anatema a todas las ciudades conquistadas. Dt 3,6 dice: «Las consagramos al anatema, como habíamos hecho con Sijón, rey de Jesbón: anatema a toda ciudad, hombres, mujeres y niños; aunque guardábamos como botín todo el ganado y los despojos de las ciudades». Más adelante, en el capítulo siete dice:

Cuando Yahveh tu Dios te introduzca en la tierra en la que entrarás para poseerla y para expulsar naciones grandes de delante de ti: hititas, guirsasitas, amorreos, cananeos, perizitas, jivitas, jebuseos. Siete naciones más grandes y más fuertes que tú, las entregue Yahveh tu Dios ante ti y las derrotes, las consagrarás al anatema. No harás alianza con ellos y no les tendrás misericordia (Dt 7,1-2) ${ }^{9}$.

La exigencia de Yahveh tiene su fundamento en que los pueblos conquistados podían atraer a los israelitas a la adoración de dioses, además, dado que Yahveh era quien daba la victoria, el botín le pertenecía por completo ${ }^{10}$. Así, la guerra propugnada por el Deuteronomio «no tiene como finalidad propagar la fe, el propósito de la guerra santa comunmente asumido por el Oeste. No era

\footnotetext{
J. P. U. Lilley, op. cit., 176.

Traducción nuestra, como todas las usadas en este artículo. Ver también Dt 2,34; 13,16; 20,17.

Ed Noort, «War in the Book of Joshua: History or Theology?», Deuterocanonical and Cognate Literature Yearbook, op. cit.
} 
extremista y no tenía interés en buscar convertidos, ni por la fuerza física ni por persuación ${ }^{11}$. Es muy posible que el jerem, siendo una costumbre antigua, haya sido limitada y justificada teológicamente por el Deuteronomio y luego por el sacerdotal (Levítico).

En la guerra contra Madián, Moisés permitió a los israelitas quedarse con las muchachas vírgenes, y con los varones adultos, pero todos los demás seres humanos debían ser asesinados y los objetos purificados con fuego o con agua (Nm 31,1-24).

Desde antes de entrar en Canaán, los israelitas sabían que Dios les entregaría todas las ciudades y que había que consagrarlas al anatema. Los siguientes textos forman algo así como una galería del terror de lo que significó la conquista para los cananeos que habitaban el lugar: Dt 10,15-18; 13,18; Jos 2,10; 6,17-18.21; 7,1-13; 8,26; 10,1.28.35.37.39.40; 11,11-12.20-21; Jc 21,11; 1 R 20,42; Is 34,5.

En Josué 6 se narra la toma de Jericó. Esta victoria es importante por ser la primera ciudad conquistada de la tierra prometida. Por ello también es necesario poner atención al anatema que se prescribe y se realiza. En Jos 6,21 se habla del anatema de los seres vivos y en Jos 6,24 el de los seres inanimados. Las excepciones se establecieron en los vv.17 (Rahab y los que estén en su casa) y 19 (el oro y la plata entrarán al tesoro de Yahveh).

El relato de la violación del anatema por parte de un israelita (Akán) en Jos 7 revela hasta qué punto Yahveh estaba decidido a no permitir que se violara ese mandato. La expedición contra Ay fue un fracaso porque un israelita había tomado como botín algo de oro, plata y un manto. En Jos 7,12 dice Yahveh: «Los hijos de Israel no podrán sostenerse ante sus enemigos. Volverán la espalda ante sus enemigos, pues se han convertido en anatema. No seguiré estando con ustedes si no exterminan el anatema entre ustedes». Quien había violado el anatema fue entregado al fuego con su familia y todo lo suyo (Jos 7,15.25). El capítulo ocho narra la derrota de Ay y la entrega de toda la ciudad al exterminio (Jos 8,26), salvando solo al ganado.

11 Reuven Firestone, op. cit., 107. 
La conquista de las ciudades de Judá, resumida en Jos 10,40-42 y 11,18-20, es, a pesar de su brevedad, el relato más impresionante de lo que significaba el anatema. He aquí los dos textos:

Josué venció a toda la tierra, la montaña, el Négueb, la Tierra Baja y las colinas con todos sus reyes. No dejó superviviente. Entregó todo lo que respira al anatema, como había mandado Yahveh Dios de Israel. Josué los venció de Cadesh Barnea hasta Gaza y a toda la tierra de Goshén hasta Guibón. Josué tomó a todos aquellos reyes de una sola vez, pues Yahveh Dios de Israel luchaba en favor de Israel. Josué, y todo Israel con él, volvió al campamento de Guilgal (Jos 10,40-42).

Josué hizo la guerra muchos días a todos aquellos reyes. No hubo ciudad que hiciera la paz con los hijos de Israel, excepto los jivitas, habitantes de Gabaón. Tomaron a todos por medio de la guerra. Pues era de Yahveh el fortalecer sus corazones para llamar a la batalla contra Israel. Para entregarlos al anatema sin que hubiera para ellos misericordia, pues eran para el exterminio según había mandado Yahveh a Moisés (Jos 11,18-20).

Sin duda que la palabra jerem se menciona más veces en el libro de Josué, por razones obvias ${ }^{12}$, pero el capítulo 20 del Deuteronomio es ilustrativo porque establece la formulación legal. En primer lugar, resalta el hecho de que el pueblo, antes de que tuviera rey, debía ser arengado a la batalla por los sacerdotes y los escribas (Dt 20,18), pues Dios mismo pelearía a favor de su pueblo (Dt 20,1). En cuanto a las naciones lejanas, Israel debía ofrecerles paz, si ellos aceptaran, se convertirían en tributarios, pero si no aceptaran, la ciudad debería ser tomada y consagrada al anatema (Dt 20,10-14). Tratándose de las ciudades de Canaán, Israel no debería ofrecerles paz, sino consagrarlas al anatema sin condiciones (Dt 20,15-18) ${ }^{13}$. Esto evitaría que los israelitas se sintieran inclinados a adorar a los dioses cananeos. «Deuteronomio y los libros pertenecientes a la tradición deuteronómica ofrecen una justificación teológica que explica el porqué de las guerras de exterminio ${ }^{14}{ }^{4}$, pero en realidad,

Aunque dicho libro ha sido también interpretado, más que como una guerra contra los antiguos habitantes de Canaán, como una guerra contra los disidentes internos durante la época de Josías. Cf. Kuan Jeffey Kan-Jin, op. cit., 189-203.

13 Parece que, en este último caso, el anatema se aplicaba solo a las personas, no a los animales. Es la opinión de José Luis Sicre, op. cit., 188.

14 Edesio Sánchez, Deuteronomio. Introducción y comentario (Buenos Aires: Kairós, 2002), 315 
la toma de Canaán, como muestra el mismo libro de Josué, no se realizó abruptamente, por medio de la guerra de exterminio ${ }^{15}$, y el jerem no se aplicó siempre en su forma extrema.

En Dt 21,10-14 trata el caso concreto de los cautivos, especialmente de una mujer, suponiendo que se podía hacer cautivos e incluso tomar a una cautiva como esposa.

En la guerra contra los amalecitas, Saúl no consagró al anatema lo mejor del ganado, por lo que Dios lo rechazó (1 S 15,9-11), aunque él explicó que dicho ganado iba a ser sacrificado precisamente a Yahveh (1 S 15,20). En realidad, por 1 R 9,21, sabemos que no todos los habitantes de las ciudades conquistadas habían sido exterminados ${ }^{16}$.

El sustantivo jerem se usa veintinueve veces en el Antiguo Testamento, de las cuales trece están en Josué. El verbo se usa 49 veces, de las cuales 14 en Josué y siete en $1 \mathrm{~S}$ 15. Curiosamente, ni el verbo ni el sustantivo se encuentran en el libro de los salmos.

\section{La institución de la monarquía}

Cuando el pueblo pidió a Samuel un rey para que los juzgara, este se disgustó, en cierta forma, porque él había pensado que sus hijos fungieran como jueces en Israel (1 S 8,1-4), pero habló de ello a Yahveh. También a Dios molestó la idea, pues el pueblo lo rechazaba a él mismo, quien reinaba sobre ellos y suscitaba al líder necesario en el momento oportuno (1 S 8,7). En su enfado, Dios hace una ironía sobre el «tipo (mishpath) de rey (mélekh) que reinará (malakh) sobre ellos» (1 S 8,9.11). La circunstancia histórica era, sin embargo, apremiante, el santuario de Silo había sido destruido y la amenaza filistea se abatía con terror sobre Israel.

15 Esto es muy importante para Michael Walzer, «The Idea of Holy War in Ancient Israel», The Journal of Religious Ethics 20 (1992): 215-218.

16 Ver también Miq 4,13; Is 34,2; Jr 50,21.26; 51,3. 
Cuando Samuel se presentó ante el pueblo, le advirtió que el rey tomaría a los hijos de los ahí presentes para «fabricar sus armas y los arreos de sus carros», contrastando las esperanzas del pueblo «danos un rey», con la realidad por venir «tomará...» (laqaj: 1S 8,10.1314.16), y haciendo caso omiso de la finalidad para la que pedían un rey: para que los juzgue ${ }^{17}$. Sin embargo, el pueblo insistió en que quería un rey para que fuera enfrente de ellos y combatiera sus combates (1 S 8,1-20). En su descripción de lo que sería el rey, Samuel aludió a Dt 17,14-17, en donde Moisés había indicado al pueblo cuáles deberían ser las características del rey, si llegaran a elegirse uno.

Samuel insistió en que el rey tomaría a los varones para llevarlos a la guerra: «Tomará a sus hijos y los destinará a sus carros y a sus caballos y tendrán que correr delante de su carro. Los empleará como jefes de mil y jefes de cincuenta; les hará labrar sus campos, segar sus cosechas, fabricar sus armas de guerra y los arreos de sus carros» (1 S 8,11-12).

En su respuesta, el pueblo solo enfoca dos actividades del rey: juzgar y hacer la guerra: «iNo!, tendremos un rey y nosotros seremos también como los demás pueblos; nuestro rey nos juzgará, irá al frente de nosotros y combatirá nuestros combates» (1 S 8,19-20).

En 1 S 10,17-24 se retoma la «corriente» antimonárquica, que concluye en el capítulo 12. Samuel se expone al juicio del pueblo en cuanto a que no ha tomado (laqaj) nada de ellos (1 S 12,3), y luego dice que Yahveh se había hecho responsable de librar al pueblo de los países opresores (1 S 12,6-11). Sin duda que la idea del redactor fue la de culpar al mismo pueblo por las desgracias que vendrían al haberse escogido un rey. Fue precisamente el temor ante las guerras lo que condujo al pueblo a pedir un rey: «Pero vieron que Najash el rey de los hijos de Amón venía contra ustedes y me dijeron: Que un rey reine sobre nosotros, siendo así que Yahveh su Dios es su rey»

17 Cf. Jerry Hwang, "Yahweh's Poetic Mishpat in Israel's Kingship: a Reassessement of 1 Samuel 8-12», Westminster Theological Journal 73 (2011): 348. Para este autor, Yahveh no da un rey como concesión a la terquedad del pueblo, sino precisamente para castigarlo. 
(1 S 12,12). El pueblo reconoció que había pecado al pedir un rey (1 S 12,19). Luego unos lo aclaman: «iViva el rey»! (1 S 10,25), y otros lo desprecian: «iQué nos va a salvar ese!» (1 S 10,27).

La corriente monárquica, por otro lado, dice que Yahveh mismo quiso que Israel tuviera un rey y que se buscó a Saúl ${ }^{18}$. Cuando Samuel lo ungió le dijo: «ìNo es Yahveh quien te ha ungido como jefe de su pueblo Israel? Tú regirás al pueblo de Yahveh y le librarás de la mano de los enemigos que le rodean» (1 S 10,1). De modo que la motivación principal, además de juzgar al pueblo, era poder convocar para la guerra. La batalla que se narra en el capítulo once, entre la visión positiva de la realeza y la negativa (capítulo 12) demuestra que esa era una de las principales motivaciones para tener un rey. El capítulo trece vuelve inmediatamente a retomar la guerra. El primer acto de Saúl ya ungido rey sobre Israel fue convocar a una guerra contra los filisteos.

\section{En los salmos reales}

Analicemos finalmente qué dicen los salmos reales sobre el derecho del rey a hacer la guerra.

Este grupo de salmos tiene la característica de que habla del rey de Israel. Se distingue del grupo de los salmos de Yahveh rey en que estos se refieren a Dios y tienen una estructura literaria definida (himno), mientras que los primeros hablan del mesías y no tienen forma literaria común, sino que se agrupan solo por el hecho de tener como tema fundamental al mesías. En los salmos, el rey estaba en estrecha relación con Dios. Una de sus funciones principales era hacer la guerra. «Las oraciones a favor del rey expresan muy bien lo que el pueblo esperaba de él. En tiempos de guerra, no esperaba, de parte del rey, nada más que verse conducido a la victoria» ${ }^{19}$.

18 Hwang subraya que en $1 \mathrm{~S} 9,17$, el verbo no es malakh sino 'atsar, que tiene connotaciones negativas: dominar, aprisionar, retener. Cf. Ibíd., 352. «Saúl no debe preocuparse por los asnos, no solo porque los asnos de su padre habían sido encontrados, ni porque Israel lo quería para ser rey, sino porque sus privilegios reales le darían pronto todos los asnos y las posesiones que quisiera». Ibíd., 354.

Jean Pierre Prévost, Diccionario de los salmos (Estella: Verbo Divino, 1991), 46. 
No hay que forzar mucho la distinción entre el reinado de Dios y el del mesías porque aunque el mesías reinara sobre Israel, era Dios mismo quien lo había puesto en el trono y quien le daba las victorias sobre las otras naciones. Así pues, entre los salmos reales (mesiánicos) y los salmos de Yahveh rey, hay una íntima conexión que conviene no dejar de lado. Yahveh siempre fue el rey de Israel ${ }^{20}$.

En el comentario a este aspecto de los salmos reales dejaré de lado la discusión sobre si estos salmos dicen algo acerca de una fiesta de entronización del rey o de la fundación de la casa real, pues es un tema marginal al que aquí abordo.

Dios y el rey

El pequeño grupo de salmos reales muestra algunas características del derecho del rey a hacer la guerra. En primer lugar, está el que Dios mismo ha establecido que todas las naciones deben servir a su pueblo Israel, y que su sometimiento está en manos del mesías.

El salmo 2 dice -y esto es importante por cuanto está puesto al inicio del salterio para dirigir la interpretación de todo el libro-:

Pídeme, y te daré en herencia las naciones,

en propiedad los confines de la tierra.

Con cetro de hierro los quebrantarás,

los quebrarás como vaso de alfarero (Sal 2,8-9).

Todos los reyes de la tierra deben servir al rey de Israel y besar sus pies. Quien habla en el salmo es el rey mismo ${ }^{21}$, quien se sabe protegido por Dios. Es posible que el día de su entronización recitara este oráculo para disuadir a los pueblos vasallos de cualquier plan de rebelión. Es importante que este salmo sea citado cuatro veces en el Nuevo Testamento (Hch 4,25-26; 13,33; Ap 2,26-27; 19,15). 
El salmo 18 solo menciona al rey en el versículo final, pero esa mención da la clave de interpretación de todo el salmo: Él «hace grandes las victorias de su rey» (Sal 18,51). Es posible que este salmo sea el resultado de dos, el primero estaría formado por los vv. 1-31 y el segundo por los vv. 32-51.

Dios libera al rey, de los ataques de los enemigos (Sal 18,18), por eso los vence:

Persigo a mis enemigos, los alcanzo,

y no vuelvo hasta exterminarlos.

Los golpeo y no pueden levantarse, caen bajo mis pies.

Me ciñes de fuerza para la batalla, haces inclinarse debajo de mí, a quienes se levantaron contra mí.

Haces que mis enemigos me den la espalda, aniquilas a quienes me odian.

Gritan pero no hay quien escuche,

Incluso a Yahveh, pero no les responde.

Los machaco como polvo al viento, como barro de las calles los pateo (Sal 18,38-43).

Las batallas aquí descritas no tendrían que ser las batallas del rey, pero, como dije antes, el versículo final dice que se trata de las guerras del rey, por lo que el salmo cobra una dimensión nueva. Dios mismo abate a los pueblos a las plantas de su elegido (Sal 18,48).

El Sal 45,6 dice:

Tus flechas son agudas, los pueblos caen debajo de ti, tus flechas en el corazón de los enemigos del rey.

No se explica quiénes son esos pueblos que han sido sometidos ni qué hubieran emprendido en contra de Israel. Se trata, seguramente, de una hipérbole para mostrar que Dios está del lado del rey que ha elegido para su pueblo. En este punto, la imaginería israelita es más sobria que la del Cercano Oriente antiguo, para quien el rey es divino; pero, por otro lado, si el rey no es Dios, es cierto que el mundo es obra suya y le pertenece, y por ello, lo entrega a 
quien quiere en dominio. En este caso, al rey de Israel. «Aquí el rey era hijo de Yahvé per adoptionem ${ }^{22}$. Kraus reporta la similitud de la teología de estos salmos con la teología real egipcia, ya que se puede demostrar que en Egipto «1. El rey es escogido y designado soberano por la divinidad en cuyo trono va a sentarse; 2 . El gran nombre que la divinidad le confirió, permanecerá en todo su poder y su fuerza; 3 . Al soberano se le confiere poder para subyugar a todos los países extranjeros» ${ }^{23}$.

El salmo 72 es una súplica por el rey, quien deberá aplastar al opresor $($ Sal 72,4$)$. Su dominio se establecerá de mar a mar y desde el gran río hasta los confines de la tierra. Se trata de un dominio universal del rey de Israel, para quien se pide el juicio de Dios (Sal $72,1)$, aunque se mencionan algunas naciones:

Ante él se postrarán los habitantes del desierto, sus enemigos morderán el polvo.

Los reyes de Tarsis y de las islas regresarán con tributos, los reyes de Sheba y Saba traerán regalos.

Se postrarán ante él todos los reyes, todas las naciones lo servirán (Sal 72,9-11).

La misión de este rey universal será establecer la paz, mirar por los pobres (Sal 72,11-12), por él «se bendecirán todas las familias de la tierra, le llamarán dichoso todas las naciones» (Sal 72,17b). «Al monarca se le transfiere el oficio de juzgar propio de Dios (v.1ss). Haciendo las veces de Yahvé, el monarca entra como redentor salvador y misericordioso ${ }^{24}$.

Si hay reyes (Sal 2,10), se supone que no han sido sometidos al cetro del rey de Israel, por ejemplo Sal 68,10: «Reprende a esa bestia de los juncos, a esa manada de toros bravos entre naciones que parecen becerros. Haz que, humillada, te lleve barras de plata; dispersa a las naciones belicosas». Por ello, el sometimiento de las naciones se dará en el futuro, pues así lo ha determinado Dios mismo. nos salmos, por ejemplo 2; 89 y 110, el rey davídico tiene características divinas.

23 Hans Joachim Kraus, op. cit., 182.

24 Hans Joachim Kraus, Los salmos. Sal 60-150. Vol. I1 (Salamanca: Sígueme, 1995), 117. 
El reinado del rey de Israel es como el reinado del mismo Dios. Esto se ve claramente en el salmo 2, en el que se dice que el rey de Israel es el ungido de Dios $(2,2)$, que es su rey $(2,6)$, y que los pueblos besarán los pies del rey o de Dios mismo (2,11-12). Varios textos del Antiguo Testamento unen estrechamente a Dios y al rey, al grado de llamarlo ángel de Dios (2 S 14,17.20; Zac 12,8) y decir que él es como Dios (Zac 12,8). Pero solo en Sal 45,7 se le llama lisa y llanamente $\operatorname{Dios}^{25}$, cosa frecuente en Canaán y Egipto. El salmo 89 es una súplica a Yahveh en favor de su pueblo. En la desgracia, se le recuerda la promesa de no retirar su amor al descendiente de David. En dicha promesa se recuerda que Dios había dicho:

Su enemigo no le tomará ventaja,

el hijo de iniquidad no lo humillará.

Aplastaré a sus enemigos ante él, golpearé a los que lo odian.

Mi fidelidad y misericordia estarán con él, por mi nombre se levantará su cuerno.

Pondré su mano en el mar, en los ríos su derecha.

Él me dirá: Tú eres mi padre, mi Dios y roca de mi salvación.

Lo convertiré en primogénito, elevado sobre los reyes de la tierra (Sal 89,23-28).

Este salmo afirma que el rey de Israel, de la mano de Dios, gobernará todo el mundo y que todos los reyes estarían bajo su mando. Yahveh mismo guerrearía en su favor.

El salmo 110 es un oráculo a favor del $\mathrm{rey}^{26}$, a quien Dios ha sentado a su diestra (Sal 110,1) y lo ha hecho sacerdote según el orden de Melkisedek (Sal 110,4; cf. Gn 14,18), es decir, se atribuyen al rey privilegios sacerdotales, seguramente en vigor durante la ocupación

25 Aunque también puede verse Is 9,5-7. En $\mathrm{Hb}$ 1,8, citando este salmo, no se dice del rey que sea Dios, sino que el trono de Dios permanece para siempre.

26 Sin duda el rey davídico, si no David mismo. Cf. David C. Mitchell, «Lord, Remember David: G. H. Wilson and the Message of the Psalter», Vetus Testamentum 4, Vol. LVI (2006) 526-548. 
jebusea de Jerusalén, aunque también después ${ }^{27}$. El hecho de que el rey haya sido engendrado como rocío, antes de la aurora (Sal 110) acerca este salmo a lo afirmado en Sal 2,7, pero sobrepasándolo, pues ahí el rey era adoptado por Dios, mientras que en el salmo 110 es engendrado por él. La imagen del rey sentado a la diestra de un Dios era común en Mesopotamia y en Egipto.

El salmo 132 es un canto que recuerda el traslado del arca a Jerusalén (Sal 132,8) y la elección de esta como sede del trono (Sal 132,12-13). Es posible que el salmo 132 sea la expresión cultual de esas dos elecciones, relatadas en 1 R 8,16 (cf. 2 S 6-7), y un eco del Sal 89,4-5, que, como el Sal 89, menciona a David cuatro veces ${ }^{28}$.

El salmo 149 es un himno que podría considerarse de Yahveh rey. Como el salmo 2, augura que Israel dominará a las naciones porque Dios está con él. En el salmo 2, dicha subyugación se haría por medio del rey, pero esa mediación no existe en el salmo 149, en donde parece que el mesías es el pueblo piadoso y fiel. Así, pues, el salterio se abre y se cierra con el derecho de Dios, delegado al rey, para subyugar a las naciones. Ambos salmos terminan afirmando que los fieles a Dios no deberían temer.

El rey y la guerra

La guerra de Yahveh, encabezada por su mesías, se debe, a veces, a que las naciones han planeado algo contra Israel, como dice el salmo 2,1. Sin embargo, no parece que el salmo se refiera a un rey en especial, parecería que idealiza la función del rey y de su poder. Esto indicaría que el salmo es mesiánico en el sentido de que se escribió cuando el pueblo no tenía rey pero sí una grande ilusión de volver a tenerlo ${ }^{29}$. 
La segunda parte del Sal 2,12, dichosos quienes se refugian en él, parece una adición que hace inclusión con el Sal 1 (v.1) con el fin de constituir, junto con él, la introducción a todo el salterio. Pero dicha conclusión choca con el contenido del salmo, pues supone que el triunfo de Yahveh y de su Mesías está en serios aprietos y no se ha podido realizar.

El salmo 21 es una súplica con acción de gracias por las victorias del rey. Al parecer, se trata del derecho que tiene el rey para defender a su nación, según los vv. 12-13:

Pues planearon un mal contra ti, planearon una trampa, pero no podrán.

Los harás volver la espalda, ajustarás tu arco contra ellos (Sal 21,12-13).

De nuevo se confunden las proezas atribuidas a Dios con las del rey (cf. vv. 9-11).

A veces, más que planear, los pueblos ya están conspirando $($ Sal 2,2). El salmo 18 parece haber surgido como acción de gracias por una experiencia de salvación particular de David. Hay huellas de liturgización, pero queda claro que el rey está satisfecho por la protección que le ha brindado Dios tanto con respecto a los agresores externos como de las intrigas de los conciudadanos. En el salmo 18, los enemigos del rey no son solo los pueblos agresores, también son ciudadanos de su reino. Los enemigos no israelitas son tratados siempre colectivamente. En ningún caso se aclara quiénes son esos agresores, queda, sin embargo, la idea de que son precisamente pueblos que han hecho mal a Israel. No se trata, pues, de conquistas para expandir el poderío de Israel, sino guerras de defensa.

El salmo 20 es una súplica por el rey, para que obtenga la victoria contra algún enemigo externo que no es mencionado. $\mathrm{Al}$ parecer, se defiende que el rey tenga el derecho de hacer la guerra. No se explica si se trata de una guerra de defensa o de ataque a los pueblos vecinos. 
Unos en un carro y otros en caballos, nosotros esperamos en el nombre de Yahveh nuestro Dios.

Ellos se doblegaron y cayeron, nosotros nos levantamos y estaremos firmes.

Oh Yahveh salva al rey, respóndenos el día que clamamos (Sal 20,8-10).

En otras ocasiones, los enemigos han subyugado a los israelitas, como en Sal 2,3.

Yahveh mismo ha prometido al rey el dominio sobre las naciones. El salmo 110 dice:

Oráculo de Yahveh a mi Señor. Siéntate a mi derecha, Hasta que ponga a tus enemigos como estrado de tus pies.

El Señor extenderá desde Sión tu cetro de poder, domina en medio de tus enemigos.

El Señor está a tu derecha, destrozará reyes el día de su ira.

Juzgará a las naciones, amontonará cadáveres, destrozará cabezas sobre la tierra enorme.

Beberá en la orilla del torrente, por eso levantará la cabeza (Sal 110,1-2.5-6).

El rey debe dominar a los pueblos que le rodean.

En el salmo 132, los enemigos del rey son mencionados solamente en el v. 18:

Vestiré de vergüenza a sus enemigos, pero sobre él brillará su corona (Sal 132,18).

De modo que Dios mismo hará que los enemigos del rey queden cubiertos de vergüenza, es decir, derrotados.

El Sal 144 es una súplica de David para obtener el auxilio divino en contra de los extranjeros (Sal 144,7.10). Al principio del salmo se habla de la guerra: 
Bendito Yahveh, mi roca,

que adiestra mis manos para la batalla, mis dedos para la pelea.

Yahveh, inclina tus cielos, desciende,

toca los montes y echarán humo.

Fulmina el rayo, dispérsalos,

lanza tus flechas, confúndelos.

Quien da salvación a los reyes,

que libera a David su siervo de la espada maligna (Sal 144,1.5-6.10).

Una vez más se habla de las pretensiones israelitas de un dominio universal.

El rey de Israel tenía, pues, el derecho de hacer la guerra, no solo defensiva, sino también para someter a otras naciones. Aunque Israel se haya visto siempre rodeado de pueblos más fuertes que él (Egipto, Asiria, Babilonia, Persia, Grecia, Roma), su destino final era el dominio universal.

\section{Conclusión}

El derecho del rey, sea Yahveh o el mesías, a hacer la guerra no se limitaba a la lucha en contra de los malvados que pudieran existir dentro del pueblo de Israel, tampoco a una guerra defensiva, esto es, limitada a defenderse de algún pueblo invasor. Su fundamento estaba en que Dios había entregado a Israel y a su rey el dominio de todo el mundo, al menos en cuanto a las expresiones se refiere.

Tratándose de los pueblos cananeos la exigencia del anatema era absoluta y se debía a que los israelitas deberían estar libres del contagio de la idolatría.

Es indudable que el concepto de guerra santa o guerra justa fue evolucionando en Israel. La conquista paulatina de la tierra de Canaán se idealizó en la época del Deuteronomio y se presentó como un exterminio de los cananeos, pero no se pudo ocultar que, en realidad, la ocupación había sido lenta y paulatina. En esa idealización se recurrió a la costumbre medio oriental del anatema, 
pero también en este caso se limitó, se suavizó en determinados casos y se le dio una justificación teológica.

Esto no explica el hecho de que se haya presentado, al menos en la síntesis teológica deuteronomista, a Yahveh y a su pueblo como verdaderos salvajes. Creo que es preciso reconocer que la Biblia fue escrita por seres humanos que son hijos de su tiempo, de su cultura y de su cosmovisión, y que es precisamente esa forma de entender el mundo y a Dios lo que plasmaron en sus escritos. Estas narraciones, dos mil quinientos años después de que fueron escritas, nos pueden parecer inapropiadas para Dios y para el pueblo elegido, pero es un hecho que a ellos, en aquella época, no les parecía lo mismo. El documento La interpretación de la Biblia en la Iglesia, que en el año 2013 cumplió veinte de haber sido publicado, expresa estos cambios de forma inmejorable:

Lo que contribuye a dar a la Biblia su unidad interna, única en su género, es que los escritos bíblicos posteriores se apoyan con frecuencia sobre los escritos anteriores. Aluden a ellos, proponen relecturas que desarrollan nuevos aspectos del sentido, a veces muy diferentes del sentido primitivo, o inclusive se refieren a ellos explícitamente, sea para profundizar el significado, sea para afirmar su realización ${ }^{30}$.

\section{Bibliografía}

Cohen, Stuart. «Unlicensed War in Jewish Tradition: Sources, Consequences and Implications». Journal for Military Ethics 3, Vol. 4 (2005): 198-213.

Firestone, Reuven. «Conceptions of Holy War in Biblical and Qur'anic Tradition». Journal of Religious Ethics 24 (1996): 99-123.

Gangloff, Frédéric. «Joshua 6: Holy War or Extermination by Divine command (Herem)?». Theological Review 1, Vol. xxv (2004): 3-23.

Hwang, Jerry. «Yahweh's Poetic Mishpat in Israel's Kingship: a Reassessement of 1 Samuel 8-12». Westminster Theological Journal 73 (2011): 341-361.

30 Pontificia Comisión Bíblica, La interpretación de la Biblia en la Iglesia, III. A. 3. 
Kan-Jin, Jeffey Kuan. «Biblical Interpretation and the Rhetoric of Violence and War». Asia Journal of Theology 23 (2009): 189-203.

Kraus, Hans Joachim. Los salmos. Sal 1-59. Vol. 1. Salamanca: Sígueme, 1993. . Los salmos. Sal 60-150. Vol. 2. Salamanca: Sígueme, 1995.

Lilley, J. P. U. «Understanding the Herem». Tyndale Bulletin 1, Vol. 44 (1993): 169-177.

Mitchell, David C. «Lord, Remember David: G. H. Wilson and the Message of the Psalter». Vetus Testamentum 4, Vol. LVI (2006) : 526-548.

Noort, Ed. «War in th Book of Joshua: History or Theology?». En Deuterocanonical and Cognate Literature Yearbook, 69-86. Berlín/New York: Walter de Gruyter GmbH, 2010.

Prévost, Jean Pierre. Diccionario de los salmos. Estella: Verbo Divino, 1991.

Sánchez, Edesio. Deuteronomio. Introducción y comentario. Buenos Aires: Kairós, 2002.

Sicre, José Luis. Josué. Estella: Verbo Divino, 2002.

Schökel, Luis y Carniti, Cecilia. Salmos I (Salmos 1-72). Traducción, introducciones y comentario. Estella: Verbo Divino, 1992.

Vermeylen, Jacques. "Sacral War and Divine Warrior in Ancient Israel. Its Reception and the Present Satate of the Question». En Deuterocanonical and Cognate Literature Yearbook, 1-34. Berlín/New York: Walter de Gruyter GmbH, 2010.

Von Rad, Gerhard. Estudios sobre el Antiguo Testamento. Salamanca: Sígueme, 1976.

Walzer, Michael. «The Idea of Holy War in Ancient Israel». The Journal of Religious Ethics 20 (1992): 215-218. 